\title{
Organization-Based Self-Esteem and Meaningful Work Mediate Effects of Empowering Leadership on Employee Behaviors and Well-Being
}

\author{
Minseo Kim and Terry A. Beehr \\ Department of Psychology \\ 101 Sloan Hall \\ Central Michigan University \\ Mount Pleasant, Michigan 48859, U.S.A.
}

Some of these data were presented at the August 2017 Academy of Management meeting in Atlanta, Georgia.

\section{Author biographies}

Minseo Kim is an I/O Psychology PhD student at Central Michigan University. Her research inte rests include occupational stress, leadership, motivation, careers, job crafting, and employee well -being.

Terry A. Beehr is a Professor of Psychology and member of the I/O Psychology faculty at Centr al Michigan University. His research interests include occupational stress, leadership, motivation, careers, and retirement. 


\begin{abstract}
Based on the conservation of resources theory and intrinsic motivation principles, this study examined the effects of empowering leadership on employees' positive and negative behaviors and well-being through two mediators, organization-based self-esteem and meaningful work, over an eight-week period. With 347 full-time employees, results from structural equation modeling demonstrated that empowering leadership was positively associated with organizationbased self-esteem and meaningful work. Organization-based self-esteem led to greater organizational citizenship behaviors and fewer deviant behaviors. Perceptions of meaningful work resulted in lower levels of emotional exhaustion and higher levels of life satisfaction. Together, these findings highlight the important roles of the two psychological states explaining why empowering leadership contributes to employees' favorable work behaviors and psychological well-being.

Keywords: empowering leadership; organization-based self-esteem; meaningful work; work behavior; psychological well-being
\end{abstract}


MEDIATORS FOR EMPOWERING LEADERSHIP EFFECTS 3

Organization-Based Self-Esteem and Meaningful Work Mediate Effects of Empowering Leadership on Employee Behaviors and Well-Being

Over the past two decades, empowerment practices have emerged as effective approaches for organizations to promote positive work outcomes by fostering employees' feelings of competence, self-determination, meaningfulness, and impact (Maynard, Luciano, D’Innocenzo, Mathieu, \& Dean, 2014; Seibert, Wang, \& Courtright, 2011). Empowerment theory suggests that leaders play a critical role in empowering employees (Maynard, Gilson \& Mathieu, 2012; Randolph \& Kemery, 2011), and leader behaviors associated with empowerment have been identified. Empowering leadership is defined as behaviors involving delegating, fostering selfleadership and responsibilities, providing autonomy and authority, promoting participation in decision making, expressing confidence in high performance, and development support through coaching and modeling (Ahearne, Mathieu, \& Rapp, 2005; Amundsen \& Martinsen, 2014; Zhang \& Bartol, 2010). Given the characteristics of empowering leader behaviors, empowering leadership is likely to be associated with favorable employee reactions, because it helps employees increase intrinsic motivation. Accordingly, many studies showed that a higher level of empowering leadership leads to positive employee outcomes, such as job satisfaction (e.g., Amundsen \& Martinson, 2015), engagement (e.g., Tuckey, Bakker, \& Dollard, 2012), performance (e.g., Sumpter, Gibson, \& Porath, 2016), and career success (e.g., Kim \& Beehr, 2017a).

However, there remain some points in question regarding the argument that more empowerment results in positive work-related outcomes; in some studies, empowering leader behaviors focusing on high autonomy in decision-making resulted in decreased work performance (Cordery, Morrison, Wright, \& Wall, 2010; Martin, Liao, \& Campbell, 2013; 
Cheong, Spain, Yammarino, \& Yun, 2016) or had no direct effects on performance (Kim \& Beehr, 2017b). Such weak relationships imply that empowering leadership may not have a direct effect, but instead may exert its effects through more proximal mediators.

To address this issue, the present study proposes two key psychological states to examine the intermediate processes that help explain why empowering leadership can result in positive individual and organizational outcomes: Individual outcomes are personal states that are important for the person's well-being (e.g., emotional exhaustion and life satisfaction), and organizational outcomes are behaviors that more directly affect the organization's effectiveness (e.g., good citizenship behaviors and deviant behaviors). One mediator in the present study is organization-based self-esteem (OBSE; i.e., the degree to which employees believe that they are valued and competent within the organization; Pierce, Gardner, Cummings, \& Dunham, 1989). The other is meaningful work (the degree to which employees view their work as significant; Rosso, Dekas, \& Wrzesniewski, 2010). Until now, the mediating roles of these psychological states in the link from empowering leadership to work behaviors and individual well-being have not been examined (Figure 1), but as we explain subsequently, there are theoretical reasons to expect them.

One benefit of positive experiences of empowering leadership may be that it can increase the likelihood of employees taking part in constructive behaviors. We expect that empowering leadership allows followers to experience self-value and a sense of responsibility, increasing their self-esteem at work, and as a result, they are more likely to perform organizational citizenship behaviors and engage less in deviant behaviors. Apart from behavioral outcomes, there may be other important consequences that are influenced by empowering leadership, and the present study examines employee well-being outcomes in the form of life satisfaction and 
emotional exhaustion. Empowering leaders encourage employees to express their opinions, let them participate in decision-making, and perform autonomously, resulting in psychological ownership and responsibility over their work, leading to a sense of meaningfulness in work. Increased feelings of meaningful work would be a pathway to promote employees' well-being, because meaningful work is considered an important resource of job-related well-being in the context of conservation of resources theory (COR; Hobfoll, 1989).

We consider the employee behaviors to be organizational outcomes, because the behaviors that employees do can help or hinder organizational goals. Conversely, we label employee well-being as individual outcomes, because it most directly benefits the employee him/herself. Given the fact that empowering leadership research has largely neglected employee psychological well-being, one way our study contributes is to advance the understanding of the effects of empowering leadership on employees as well as on organizations. Our study uncovers underlying mechanisms linking empowering leadership with good and bad behavioral and wellbeing outcomes by considering two mediators.

\section{Empowering Leadership Relating to OBSE and Meaningfulness}

Previous research has shown that OBSE may be significantly affected by autonomy, job control, perceived organizational support, and leader-member exchange (Bowling, Eschleman, Wang, Kirkendall, \& Alarcon, 2010; Ferris, Brown, \& Heller, 2009; Naus, van Iterson, \& Roe, 2007; Sekiguchi, Burton, \& Sablynski, 2008). We argue that empowering leadership behaviors promote these causes of OBSE, a form of intrinsic motivation inspiring employees' positive accomplishment. Specifically, empowering leadership places emphasis on employees' autonomy and development and encourages them to develop the skill and self-confidence for exercising decision-making in their jobs (Ahearne et al., 2005; Amundsen \& Martinsen, 2014; Vecchio, 
Justin, \& Pearce, 2010). Increased job authority and autonomy may convey to employees that they are trusted and worthy organization members. Additionally, empowering leader behaviors, such as offering personal and professional challenges with high standards allow employees to experience self-value and competence, and such experience further helps to develop their selfesteem at work. Empowering leadership signals to followers that their leader has confidence in their abilities and is willing to provide them with necessary resources. Support (e.g., coaching, consulting, and feedback) and positive evaluations from the leader can be an important determinant of self-esteem in organizational contexts, because followers consider themselves as valuable members when leaders recognize their competence and give favorable evaluation and feedback to them.

H1. Empowering leadership is positively related to organization-based self-esteem. Empowering leadership may also play a role in shaping the meaningful work of employees. According to Steger, Dik, and Duffy's (2012) conceptualization, definitions of meaningful work have three aspects: Positive meaning in work represents that work is significant, worthwhile, and has positive personal meaning (Rosso et al., 2010); meaning making through work indicates that work is a key avenue for developing meaning, and life as a whole can become more meaningful by doing meaningful work (Steger \& Dik, 2010); greater good refers to the perception that meaningful work has a broader positive impact on others (Grant, 2007). Meaningful work is considered to arise when people have an understanding of their abilities, what is expected of them, and how to function successfully in their work environments (Steger \& Dik, 2009). Thus, meaningful work will be experienced when people recognize their efforts are integral to the organization's goals or function, as well as to the greater good of others 
MEDIATORS FOR EMPOWERING LEADERSHIP EFFECTS 7

in general, for example by helping the organization provide a good or service that is valued by others.

Empowering leadership is likely to create working conditions that can boost employees' sense of meaningfulness in their work. It gives employees psychological identification with the work by encouraging them to participate in important decision making, to autonomously selfmanage their work, and to be accountable for work outcomes in their organization. Employees therefore can make meaningful contributions to the organization, which further increases their understanding of their role within it. Prior studies suggested that jobs with higher levels of autonomy led to more experienced meaningfulness of work (Deci \& Ryan, 2000; Hackman \& Oldham, 1980). That is, employees find work meaningful when they are able to pursue important goals and have autonomy in the decision-making process leading to goal completion. Empowering leaders can help employees experience such meaning by providing them with more autonomy.

Empowering leadership also gives employees opportunities to learn new things, emphasizing self-development (Tuckey et al., 2012), which makes them feel a sense of belongingness. Research on meaningful work suggested that belongingness plays a role in the construction of meaningfulness (Rosso et al., 2010). Because people are motivated to be a part of desirable social groups, feelings of connection to groups through work provide employees with meaningfulness by helping them experience a positive sense of shared common identity with others (Kahn, 2007; Pratt \& Ashforth, 2003; Rosso et al., 2010; Wrzesniewski, Dutton, \& Debebe, 2003). Empowering leadership highlights the joint decision making by leaders and their followers, promoting collaboration and information sharing (Arnold, Arad, Rhoades, \& Drasgow, 2000; Konczak, Stelly, \& Trusty, 2000), which fosters positive interactions and communication 
among employees, also resulting in higher levels of experienced meaning. Although there is little empirical research linking overall empowering leadership to the meaningful work, positive correlations between variables resembling specific empowering leader behaviors (e.g., participation, coaching, informing, and interacting) and meaning (one of four components of psychological empowerment; Spreitzer, 1995) were found $(r=.28$ to $r=.30)$ in a study by Dewettinck and van Ameijde (2011). Taken together, the theoretical reasoning and some limited but related empirical evidence suggest that empowering leadership has a positive relationship with employees' experience of meaningful work.

H2. Empowering leadership is positively related to meaningful work.

\section{Consequences of Organization-Based Self-Esteem and Meaningful Work}

Organization-based self-esteem (OBSE) and meaningful work have been proposed to be related to a variety of work outcomes that benefit individuals and organizations. The present study examines two organizationally relevant behaviors and two individual well-being outcomes. The model in Figure 1 proposes that OBSE is a feature of intrinsic motivation that can affect employees' behavioral responses (Pierce \& Gardner, 2004). Two important employee behaviors, one that benefits the organization and one that hinders the organization, are especially likely to be influenced by intrinsic motivation, because they are either positive but not explicitly recognized by extrinsic reward systems (organizational citizenship behaviors, OCBs) or are negative and usually hidden from view (deviant behaviors). OBSE will result in more OCBs, or actions going beyond the job descriptions, in order to help one's organization and coworkers (Williams \& Anderson, 1991), and it will result in fewer deviant behaviors (behaviors that violate organizational norms and threaten the well-being of the organization, its members, or both; Bennett \& Robinson, 2003). There is some empirical support for this proposition. For 
example, employees who viewed themselves as organizationally valuable engaged in cooperative behaviors that were desired by the organization (Bowling et al., 2010; Gardner \& Pierce, 2016; Van Dyne, Vandewalle, Kostova, Latham, \& Cummings, 2000).

In addition to promoting good (citizenship) behaviors, feelings of OBSE may also serve to inhibit employees from engaging in bad (deviant) acts against the organization and individuals in it, because employee deviance occurring within the organization is inconsistent with feelings of being valued in the organization. We expect that OBSE would motivate employees to avoid or reduce bad behaviors that may harm the organization or people in organization. Supporting these arguments, thwarted esteem needs and feelings of belonging in organizations, which are similar to low OBSE levels, led to more interpersonally harmful and fewer helpful behaviors (Thau, Aquino, \& Poortvliet, 2007), and OBSE itself was found to be negatively associated with deviance (Ferris et al., 2009; Whelpley \& McDaniel, 2016). Overall, it is expected that feelings of OBSE lead organizational members to adopt behaviors that are beneficial to the individual and organization, as well as to discourage them from exhibiting undesirable behaviors.

H3. Organization-based self-esteem is positively related to organizational citizenship behaviors.

H4. Organization-based self-esteem is negatively related to deviant behaviors.

Thus, based on intrinsic motivation principles, we posit that OBSE will motivate employee behaviors that are important to the organization. Based on COR theory, we propose that the other mediator in the model in Figure 1, meaningful work, is a resource likely to result in outcomes that represent the well-being of the person. Perceptions of meaningful work may decrease feelings of emotional exhaustion and increase life satisfaction. Emotional exhaustion, a core element of burnout, is defined as "feelings of being overextended and depleted of one's 
emotional and physical resources" (Maslach, Schaufeli, \& Leiter, 2001, p. 399). Life satisfaction refers to a cognitive and global assessment of a person's quality of life as a whole (Diener, Emmons, Larsen, \& Griffin, 1985; McDowell, 2010).

The theoretical rationale for the proposed hypotheses for meaningful work can be found in the conservation of resources theory (COR; Hobfoll, 1989; 2001). COR theory emphasizes the positive role of job resources in the relationship between job demands and well-being. The nature of work, including meaningful work, is a job resource promoting and protecting employees' well-being. Meaningful work may help employees persist in the face of job demands and even facilitate recovery of well-being. The experience of positive emotions and meaning coming from the job contribute to increased energy and enable employees to better handle work-related issues (Crawford, LePine, \& Rich, 2010). Thus, employees who perceive their job as meaningful may be less vulnerable to emotional exhaustion, a facet of burnout. Maslach et al. (2001) linked meaningful work with burnout theoretically; empirical research showed that the perceived importance of the work (a variable similar to meaningfulness) led to low levels of burnout experiences in an Israeli sample (Pines \& Zaidman, 2014), and meaningful work is negatively related to amotivation (a psychological state similar to burnout; Allan, Autin, \& Duffy, 2016). We predict that meaningful work may improve employee well-being by reducing emotional exhaustion, a facet of burnout.

H5. Meaningful work is negatively related emotional exhaustion.

Finally, we also expect meaningful work to positively affect employee well-being in the form of life satisfaction. A feeling of life satisfaction can be influenced by many antecedents in the work and family domains (Diener \& Fujita, 1995; Steel, Schmidt, \& Shultz, 2008). More specifically, emotions experienced in one life domain (e.g., work) spill over into other life 
MEDIATORS FOR EMPOWERING LEADERSHIP EFFECTS 11

domains (e.g., life in general) such that individuals enjoying their work and feeling happy make a positive judgment about their overall lives (Judge \& Watanabe, 1994). Greenhaus and Powell (2006) showed how resources derived from the work role affect ones life beyond the workplace.

Several studies argued that deriving meaning from work experiences is related to overall positive experiences such as life satisfaction (e.g., Myers \& Diener, 1995; Steger \& Dik, 2010; Steger et al., 2012). Important and meaningful jobs may be an important source of meaning in life in general. That is, employees who experience a sense of purpose and meaning in their work are likely to take a more positive outlook on their lives, which results in increased well-being in the form of life satisfaction.

H6. Meaningful work is positively related to life satisfaction.

\section{Mediating Roles of OBSE and Meaningfulness}

The previous hypotheses are summarized and organized by Figure 1, but an important feature of that model is the hypotheses that OBSE mediates the relationships of empowering leadership with employees' favorable and unfavorable behaviors based on intrinsic motivation theories, and that meaningful work mediates the relationships of empowering leadership with employees' favorable and unfavorable well-being based on COR theory. Thus, we test these mediation processes in which empowering leadership is linked to favorable and unfavorable individual and organizational outcomes to the extent that it develops OBSE and meaningful work for employees.

H7. Organization-based self-esteem mediates the relationship between empowering leadership and a) organizational citizenship behavior and (b) deviant behavior. H8. Meaningful work mediates the relationship between empowering leadership and (a) emotional exhaustion and (b) life satisfaction. 
MEDIATORS FOR EMPOWERING LEADERSHIP EFFECTS 12

\section{Methods}

\section{Participants and Procedure}

This study was approved by the university's Institutional Review Board (IRB). Data were collected in three waves with a four-week time lag between measurement points through Amazon's Mechanical Turk (MTurk) sample. MTurk provides a large paid pool of potential survey respondents who vary greatly in some characteristics including jobs and geographic locations, making their data potentially widely representative of leadership situations. Previous research on leadership has successfully employed a time lag of four weeks between measurements (e.g., Kim \& Beehr, 2017c; Tang, Kwan, Zhang, \& Zhu, 2016), and therefore a four-week interval was chosen for the present study.

Recent studies suggested that MTurk workers tend to read survey instructions carefully and to be representative of US population characteristics in terms of age, ethnicities, education, and work experience, providing high-quality data that are at least comparable to those from other data sources (Behrend, Sharek, Meade, \& Wiebe, 2011; Goodman, Cryder, \& Cheema, 2013; Ramsey, Thompson, McKenzie, \& Rosenbaum, 2016). For example, MTurk data were shown to be better in quality than two professional marketing services, including one finding that the data were better than those provided by QUALTRICS, a similar data source (Kees, Berry, Burton, \& Sheehan, 2017).

We required respondents to be full-time employed adults aged 18 and older, working in the US (measured through disqualification items - working 30 hours or more per week), and holding a 95\% approval rating from previous Mturk assignments, consistent with existing

recommendations (e.g., Buhrmester, Kwang, \& Gosling, 2011; Mason \& Suri, 2012). Regarding the approval ratings, a particular advantage of MTurk is that researchers can opt for contacting only the most reliable participants, those who have been the most conscientious on past surveys 
according to previous researchers (Casler, Bickel, \& Hackett, 2013). Data from participants with high approval ratings have higher reliability, pass attention-check questions at a higher rate, and have lower social desirability scores (Peer, Vosgerau, \& Acquisti, 2014).

Furthermore, we used several procedures in order to control the quality of the data (Cheung, Burns, Sinclair, \& Sliter, 2017; DeSimone, Harms, \& DeSimone, 2015). First, we blocked IP addresses after completion of the survey to avoid multiple completion attempts of participants. Second, the survey contained several reverse-coded and attention check items, which allowed us to screen out non-purposeful responses. Third, we eliminated data with apparently low effortful responding: participants who selected many of the same responses $(90 \%)$ and completed the survey more than three times as fast as the average time. Finally, we removed outliers for each scale, with cutoff 3.0 standard deviations from the mean as well as multivariate outliers with the use of Mahalanobis distances.

Initially, 790 employees completed the first survey. Among them, we excluded 159 disqualified (e.g., Non-US full-time employee) and partial completions (more than 60\% missing data). We also eliminated 36 non-purposeful and low effort responses, leaving usable data from 595 respondents to the first survey. Of these, 498 responded to the second survey four weeks later; data for 51 of them were dropped due to low effort responding, failed attention checks, and mismatched codes between time 1 and time 2 . We thus invited 447 participants to the third survey four weeks after the second survey. Of these, 376 completed the final survey; 29 responses were deleted due to outliers and mismatched codes across time points.

We compared demographic differences among the three samples to assess whether the final sample (Time 3) was representative of the Time 1 and Time 2 samples. We found no big differences with respect to demographic variables (age, gender, and education) assessed at Time 
1, Time 2, and Time 3. Accordingly, we could not find reasons to suspect any severe systematic sample bias due to attrition across the three surveys. Furthermore, we note that such attrition is not unusual; recent published leadership studies in which data were collected in multiple time points have commonly reported data containing similarly high attrition rates of respondents across multiple data collections (e.g., Audenaert, Vanderstraeten, \& Buyens, 2017; Kim \& Beehr, 2017a; Marstand, Martin, \& Epitropaki, 2017).

Therefore, the hypotheses were tested with a final sample of 347 responses: $55.2 \%$ were male, $79.3 \%$ white, and $67.9 \%$ had at least a bachelor's degree. The mean age of participants was 35.39 years $(S D=9.55)$, and they worked an average of 40.60 hours in a week $(S D=7.75)$ and in their current organization for an average of 6.54 years $(S D=5.64)$. They were employed in a variety of industries (e.g., education, technology, and finance); and 59.1\% were line employees, 19.2\% supervisors, $15.9 \%$ managers, and 5.8\% upper managers or executives.

\section{Measures}

The measures were taken at different times in order (1) to reduce the possible effects of common method variance on the relationships among the variables (Podsakoff, MacKenzie, \& Podsakoff, 2012) and (2) to measure the variables in a sequence matching the proposed causal model in Figure 1. The predictor, empowering leadership, was measured at Time 1, the two mediators, meaningful work and organization-based self-esteem, were measured at Time 2, and the outcomes, work behaviors and psychological well-being, were measured at Time 3 . Two dispositional control variables were included in the present study: negative affectivity and social desirability, both measured at Time 2 .

Empowering leadership (T1). For empowering leadership, we used Zhang and Bartol's (2010) 12-item measure $(\alpha=.90)$. It includes four dimensions: autonomy (e.g., "My supervisor 
allows me to do my job my way"), meaningfulness of work (e.g., "My supervisor helps me understand how my objectives and goals relate to that of the company"), participation in decision making (e.g., "My supervisor makes many decisions together with me"), and confidence in high performance (e.g., "My supervisor expresses confidence in my ability to perform at a high level"), rated on a 5-point Likert scale from 1 (strongly disagree) to 5 (strongly agree).

OBSE and meaningfulness (T2). Two psychological states, organization-based selfesteem (OBSE) and meaningful work, were the mediators. OBSE was measured with ten items $(\alpha=.91)$ developed by Pierce et al. (1989). An example item is "I am valuable in this organization" rated on a 7-point Likert scale from 1 (strongly disagree) to 7 (strongly agree). Meaningful work $(\alpha=.96)$ was assessed with Steger et al.s (2012) ten-item Work as Meaning Inventory. The scale captures three dimensions of meaningful work including positive meaning (e.g., "I have found a meaningful career"), meaning making through work (e.g., "I view my work as contributing to my personal growth"), and greater good motivation (e.g., "The work I do serves a greater purpose"). Respondents rated items on a scale from 1 (absolutely untrue) to 7 (absolutely true).

Organization-relevant behavioral outcomes (T3). Two aspects of employees' work behaviors were measured: organizational citizenship behaviors (OCBs) and workplace deviance. OCBs were measured with the fourteen-item scale $(\alpha=.84)$ developed by Williams and Anderson (1991). Seven behaviors were directed at individuals (OCB-I) and seven others at the organization (OCB-O). Respondents indicated the extent to which they engage in certain activities using a 7-point Likert scale from 1 (strongly disagree) to 7 (strongly agree). Example items for OCB-I and OCB-O include "I help others who have heavy workloads" and "I conserve and protect organizational property," respectively. 
Deviant behaviors were measured with the nineteen-item scale $(\alpha=.94)$ developed by Bennett and Robinson (2000). Interpersonal deviance was measured with seven items, and organizational deviance was measured with twelve items. Example items include "Said something hurtful to someone at work" (interpersonal deviance), and "Taken an additional or longer break than is acceptable at your workplace" (organizational deviance). Respondents were asked to rate the extent they had participated in each behavior using a 7-point Likert scale from 1 (never) to 7 (daily).

Individual well-being outcomes (T3). Emotional exhaustion was measured with the fiveitem $(\alpha=.95)$ Maslach Burnout Inventory's (MBI-GS) emotional exhaustion subscale (Schaufeli, Leiter, Maslach, \& Jackson, 1996). An example item is "I feel used up at the end of the work day" answered on a 7-point scale from 1 (never) to 7 (every day).

Life satisfaction was assessed using the five-item $(\alpha=.92)$ Satisfaction with Life Scale (SWLS; Diener et al., 1985). An example item is "In most ways my life is close to my ideal" rated on a 7-point Likert scale from 1 (strongly disagree) to 7 (strongly agree).

Control variables: Social desirability and negative affectivity. We measured two dispositional variables to use as controls. First, because self-reports of good and bad behaviors may be influenced by a desire to present one's self in a favorable light, we decided to control for social desirability when predicting these behaviors. Second, because emotional exhaustion and life satisfaction are expected to be state affective variables, we controlled for trait affect in the form of negative affectivity when predicting them. We also note that, because social desirability and negative affectivity were measured from the same source as the other variables (the employee), using them as control variables helped to control not only for the socially desirability and negative affectivity constructs but also for common method (source) variance, similar to the 
marker-control approach recommended by Podsakoff et al. (2012).

Social desirability was measured at Time 2 using the five-item $(\alpha=.73)$ Socially Desirable Response Set (SDRS; Hays, Hayashi, \& Stewart, 1989). An example item is "No matter who I'm talking to, I am always a good listener." Respondents rated items on a 5-point Likert scale from 1 (definitely true) to 5 (definitely false).

Negative affectivity was measured at Time 2 using the ten-item $(\alpha=.92)$ Positive and Negative Affect Scale (PANAS; Watson, Clark, \& Tellegen, 1988). Respondents indicated how they feel regarding each of 10 affects (e.g., irritable, distressed, and nervous) on a 5-point Likert scale from 1 (not at all) to 5 (extremely).

\section{Results}

Table 1 presents means, standard deviations, reliabilities, and correlations of all the variables. Correlations corresponding to the paths in the hypothesized model were significant. Empowering leadership was positively related to the two mediators, meaningful work $(r=.40)$ and OBSE $(r=.45)$. The mediator OBSE was significantly related to OCBs $(r=.44)$ and deviant behavior $(r=-.14)$, and meaningful work was related to emotional exhaustion $(r=-.25)$ and life satisfaction $(r=.27)$.

\section{Hypotheses and Model Testing}

We used LISREL 8.8 (Jöreskog and Sörbom, 2006) to obtain model fit and parameter statistics. For the full SEM with latent variables, four subscales of empowering leadership and three subscales of meaningful work served as indicators. Similarly, subscales were used as manifest indicators of the OCBs and deviance, which had two subscales each. The 10-item measure of OBSE had no subscales and was randomly parceled (two parcels consisting of three items and one parcel consisting of four items). Emotional exhaustion and life satisfaction had no 
subscales and only five items each (making parceling less viable), and their items served as indicators.

The measurement model results indicated a good fit to the data $\left(\chi^{2}[438]=1147.98, p\right.$ $<.01 ; \mathrm{RMSEA}=.07 ; \mathrm{CFI}=.96 ; \mathrm{IFI}=.96 ; \mathrm{NNFI}=.95)$, providing evidence that further examination of the structural model in Figure 1 was justified. Table 2 contains all the model fit indices for the study. Structural modeling results suggested that the hypothesized model fit the data well $\left(\chi^{2}[454]=1461.33, p<.01 ; \operatorname{RMSEA}=.08 ; \mathrm{CFI}=.94 ; \mathrm{IFI}=.94 ; \mathrm{NNFI}=.93\right)$. Figure 2 presents the overall structural model with standardized path coefficients. Empowering leadership was positively related to $\operatorname{OBSE}(\beta=.55, p<.01)$ and meaningful work $(\beta=.54, p<.01)$, supporting hypotheses 1 and 2. The results also supported hypothesis 3, that OBSE would be positively related to OCBs $(\beta=.53, p<.01)$, as well as hypothesis 4 , that OBSE would be negatively related to deviant behaviors $(\beta=-.14, p<.01)$. Additionally, hypotheses 6 and 7 were supported, because meaningful work was negatively related to emotional exhaustion $(\beta=-.29, p$ $<.01)$ and positively related to life satisfaction $(\beta=.32, p<.01)$.

Regarding the two control variables, social desirability and negative affectivity, the correlations of social desirability with OCBs and deviant behaviors were moderate $(r=.37$ for OCBs and $r=-.28$ for deviance at the $p$ value of .01; Table 1). Negative affectivity also moderately correlated with emotional exhaustion $(r=.32, p<.01)$ and life satisfaction $(r=-.30$, $p<.01)$. We therefore included these two control variables in the analyses; we note, however, neither control variable significantly affected the conclusions in the present study, although some path coefficients decreased after controlling for them. In order to make the results in Figure 2 more reader-friendly, we omitted the control variables from the figure. In summary, the results supported the model in Figure 1, suggesting that empowering leadership may have indirect 
MEDIATORS FOR EMPOWERING LEADERSHIP EFFECTS 19

effects on employees' work behaviors via OBSE and on psychological well-being via meaningful work. Further testing of the specific mediation links is reported below.

\section{Alternative Models}

The first alternative overall model added two direct paths from the mediator, OBSE to psychological well-being (emotional exhaustion and life satisfaction) and two direct paths from meaningful work to employee work behaviors (OCBs and deviant behaviors; alternative model 1), Alternative model 1 therefore allowed examination of the hypothesized model's assumption that each of the two mediators is uniquely related only to two of the outcomes (either organizationally relevant behaviors or individual well-being outcomes). The additional paths for alternative model 1 did not improve or change any fit indices (Table 2), and none of additional four paths were significant $\left(\Delta \chi^{2}[4]=2.86, p=.58\right)$. Therefore, the proposal that OBSE may mediate uniquely for organizationally relevant behaviors and meaningfulness may mediate uniquely for individual well-being was supported.

For further evidence about mediation, we tested a second alternative model adding four direct paths from empowering leadership to the work behaviors and psychological well-being variables (alternative model 2). For alternative model 2, empowering leadership had direct effects on the well-being outcomes of emotional exhaustion $(\beta=-.32, p<.01)$ and life satisfaction $(\beta=.17, p<.01)\left(\Delta \chi^{2}[4]=31.20, p=.00\right)$; it did not have significant direct effects on the two behavioral outcomes however. This means that in addition to the indirect effects, empowering leadership also may have direct effects on psychological well-being, but not on organizationally relevant behaviors. Furthermore, emotional exhaustion was no longer affected by meaningful work after adding a direct path from empowering leadership. The path coefficient between meaningful work and life satisfaction also decreased from $\beta=.32$ to $\beta=.22$. However, 
MEDIATORS FOR EMPOWERING LEADERSHIP EFFECTS 20

we retained the hypothesized mediation model as the ideal and parsimonious model, given no noticeable improvement in fit at two decimal places (Table 2).

\section{Mediation and Bootstrapping}

Finally, for more rigorous tests of the mediation proposed in hypotheses 7 and 8 , bootstrapping analyses were calculated using PROCESS macro, a computational tool for mediation analysis (Hayes, 2013). Table 3 presents the direct effects and bootstrapped estimates for the indirect effects with $95 \%$ confidence intervals.

Following the recommendations of Preacher and Kelley (2011), $k^{2}$ (Kappa-squared) is reported as a mediation effect size. The $k^{2}$ is not sensitive to sample size, because the $k^{2}$ is the ratio of the indirect effect to the maximum possible size of the indirect effect given the constraints of the data (Hayes, 2013). To determine the criteria for describing the magnitude of effect sizes, Cohen's guidelines defining small (.01), medium (.09), and large (.25) effect sizes were considered (Preacher \& Kelley, 2011). OBSE significantly mediated the relationships between empowering leadership and the two behavioral outcomes, because their confidence intervals did not include a zero, supporting mediation effects (Table 3). Meaningful work also significantly mediated between empowering leadership and psychological well-being, because those confidence intervals also did not include zero. There were, however, also direct effects $(\beta=$ -.87, $p<.01$ for emotional exhaustion; and $\beta=.34, p<.05$ for life satisfaction).

As an example, the model included OBSE as a mediator of the relationship between empowering leadership and OCB. As seen in the first row of Table 3, the direct effect from empowering leadership to OCB was not significant $\left(c^{\prime}=.07, p=.29\right)$. However, the indirect effect of empowering leadership on OCB via OBSE was significant ( $a b=.22, C I(95 \%)$ : LL $\left.=.15, \mathrm{UL}=.30, k^{2}=.17\right)$, and the effect size of $k^{2}$ can be interpreted as medium to large with 
MEDIATORS FOR EMPOWERING LEADERSHIP EFFECTS 21

reference to Cohen's standard. Overall, both the model fit statistics and the bootstrapping results supported the proposition that OBSE and meaningful work mediated the relationships of empowering leadership with the four criteria, OCB, deviance, emotional exhaustion, and life satisfaction.

\section{Discussion}

The purpose of the present study was to provide a better understanding of why empowering leadership could influence employees' engagement in organizationally relevant behaviors and improve their psychological well-being. As a form of intrinsic motivation, OBSE transfers benefits from empowering leadership to employee behaviors, and as a resource based on COR theory, meaningful work transfers the effects of empowering leadership to the individual's well-being.

Empowering leadership of supervisors involves behaviors that promote followers' intrinsic motivation through the delegation of authority and challenging tasks, facilitation of selfleadership, as well as support for employees' growth and development (Amundsen \& Martinsen, $2014 ; 2015)$. The resulting increased OBSE leads to a willingness among employees to perform helpful behavior for their coworkers and organization, exhibiting a high level of organizational citizenship behaviors and a low level of deviance. This result was consistent with previous research showing that self-evaluation at work (OBSE) was an important source of intrinsic motivation linking to employees' behavioral outcomes (Bowling et al., 2010; Pierce et al., 1989). Thus, the present study explains why empowering leader behaviors could contribute to generating positive work behaviors. How employees evaluate themselves at work is an important driver of work behaviors, and it is influenced by empowering leadership. Consistent with the mediation model, we found indirect effects, and there was no significant direct effect between 
MEDIATORS FOR EMPOWERING LEADERSHIP EFFECTS 22

empowering leadership and either OCBs or deviant behaviors. By helping employees gain feelings of self-worth at work, empowering leaders may promote their OCBs and decrease workplace deviance.

Meaningful work, a job resource in COR theory, appeared to facilitate the individual employee's well-being, indicating that the benefits of meaningful work are not limited to the organizational outcomes. We found that employees who judged their work to matter and to be meaningful were more satisfied with life as a whole and less emotionally exhausted than those who felt that their work was meaningless, which was consistent with the previous argument that the importance of one's work could serve a protective function against burnout and mental health problems (Blustein, 2008; Pines \& Zaidman, 2014). These findings also underlined the importance of empowering leader behaviors for the development of job resources for employees. Significant direct relationships of empowering leadership with the well-being indicators of emotional exhaustion and life satisfaction were also found. Maslach et al. (2001) found higher levels of burnout for individuals who have little participation in decision making, which is the opposite of some parts of empowering leadership. The direct effects of empowering leadership on well-being in the present study indicate that empowering leadership itself may be a causal factor in employee well-being, or that additional mediators besides meaningful work may be needed to explain its effects on well-being. From the perspective of COR theory, followers of empowering leaders are likely to be able to obtain, retain, and foster the necessary resources and energy, thereby preventing impaired well-being.

\section{Contributions}

The present study contributes to the literature on empowering leadership in multiple ways. Although past research has examined the influence of empowering leadership on 
employees' behaviors, mainly focused on in-role performance and extra-role behaviors (e.g., meta-analysis by Kim, Beehr, \& Prewett, 2018), its effects on employee negative behaviors (workplace deviance), as well as on psychological well-being remained untested. The present study, therefore, extended this line of research (1) by considering dual mediators (motivationrelated OBSE and resource-related meaningfulness) and (2) by testing the effects on both good and bad behavioral and well-being outcomes. Empowering leader behaviors contributed to shaping the construction of employees' self-evaluation (OBSE) at work, which was a proximal motivator of employees' behaviors. Given the fact that there is no direct effect of empowering leadership on OCBs and deviant behaviors, OBSE fully explains why empowering leaders' followers put in extra work in the form of OCBs (and perform fewer deviant behaviors).

The present study also showed that empowering leader behaviors can result in more meaningful jobs. COR theory suggests that having some resources can help in obtaining more resources (a resource spiral); empowering leadership can be seen as a resource by the employee, and it leads to the experience of meaningful work, another resource. In addition, that empowering leadership had a direct effect as well as indirect effects on followers' well-being is consistent with the concept of empowering leadership itself being a resource (because it has direct effects on well-being as well as helping to gain other resources such as meaningful work). Therefore, empowering leadership may be a key resource capable of promoting employee wellbeing, even though previous empirical evidence on employee well-being seems to have neglected the role of empowering leadership. Additionally, previous studies have mainly linked meaningful work to performance, engagement, and career commitment (Duffy, Dik, \& Steger, 2011; Harris, Kacmar, \& Zivnuska, 2007; Steger, Littman-Ovadia, Miller, Menger, \& Rothmann, 2013). However, our study provided empirical evidence to support that empowering leadership 
MEDIATORS FOR EMPOWERING LEADERSHIP EFFECTS 24

and meaning of work may also influence employees' life satisfaction, as well as emotional exhaustion.

\section{Practical Implications}

The present study focused on organization-specific self-esteem, OBSE, because it may be more closely related to organization-related phenomena and thus may provide a better explanation for organizationally relevant behaviors compared to other self-evaluation constructs, including generalized self-efficacy and global self-esteem. Organizations that are concerned with increasing engagement in citizenship behaviors and decreasing occurrence of deviant behaviors would benefit from paying more attention to the level of OBSE of employees. Employees with high levels of OBSE perceive that they play a valuable and competent role in the organization. Such a positive self-concept is likely to motivate employees to engage in beneficial behaviors and reduce harmful behaviors directed toward coworkers and the organization. Self-evaluation and self-perceived competency in the organization may be socially determined and shaped by interactions with others such as a supervisor and coworker. That is, employees' self-worth as an organization member may be formed through inferences drawn from how leaders treat them (McAllister \& Bigley, 2002). Authoritarianism, with lack of supervisory support, was found to be a threat to followers' self-identity, eventually undermining their self-esteem (Chan, Huang, Snape, \& Lam, 2013; Ferris et al., 2009). On the contrary, our study found that empowering leadership behaviors including power sharing, recognition, and guidance, signal to followers that they are valuable and competent, leading to a high self-evaluation. Therefore, empowering leadership can be a way to promote employees' senses of self-worth to promote favorable behaviors. 
MEDIATORS FOR EMPOWERING LEADERSHIP EFFECTS 25

Managers should also realize the importance of shaping the workplace environment to promote meaningful work for employees. Employees' perception of meaningful work may not only assist in reducing negative aspects of work such as burnout, but it may also increase their life satisfaction, thereby contributing to improving employees' overall well-being.

In summary, employees working with empowering leaders show more extra-role behaviors and higher life satisfaction, as well as are less likely to burnout and engage in workplace deviance. The beneficial effects of empowering leadership may occur through increased intrinsic motivation and psychological resources. Therefore, increasing employees' OBSE and meaningful work could be a useful human resource management practice and/or occupational health strategy.

\section{Limitations and Future Research}

A methodological limitation of the present study is the possibility of single-source bias. We measured study variables at separate points in time and also controlled for the influence of social desirability and negative affectivity, both of which help reduce common method effects (Podsakoff, et al., 2012). Nevertheless, future research could further guard against common method effects by collecting data from managers or coworkers, or by manipulating predictor variables (leadership) in experimental designs (e.g., in the form of leader training). Some of the variables in the study (i.e., the control and mediator variables), however, are by nature internal psychological constructs that the person him/herself may know best.

Although the participants worked in a wide range of industries, the results may not generalize widely, because about two-thirds of them were college graduates, and about $40 \%$ of them were in supervisor, manager, or executive positions. Future studies, therefore, should try to replicate our results with a sample from other educational levels (e.g., blue collar vs white collar 
MEDIATORS FOR EMPOWERING LEADERSHIP EFFECTS 26

employees). If the study had employed a narrower sample (e.g., leaders in a single organization or at least a single industry), readers could judge that the results would apply to their work setting to the extent that their own setting resembled the one in the study. On the other hand, if the study had employed a broader sample (e.g., a representative national sample), no specific leader could be very certain that the results applied to their own setting, but they would apply to an "average" leadership setting. The current sample was broad and closer to the second, broader example than to the narrower one, but the sample was not drawn to be truly representative of leaders nationally.

We examined both a negative (emotional exhaustion) and a positive (life satisfaction) form of psychological well-being in order to provide a balanced approach of employee wellbeing associated with empowering leadership. However, there are many other potential wellbeing outcomes that could be explored to provide better understanding of the influence of empowering leadership; examples include employees' physical health and health behaviors such as smoking and alcohol consumption. Similarly, we tried to examine employee behaviors as an outcome broadly by including both positive and negative behavior, but there are many other employee behaviors that are also worthy of study, including in-role performance and withdrawal behaviors.

\section{Conclusion}

Employees' OBSE and experience of meaningful work are related to greater involvement in organizationally relevant behaviors and well-being, respectively. Empowering leadership can enhance both OBSE and meaningfulness, thereby resulting in favorable outcomes for both the organizational and the individual. Therefore, empowering leadership is a powerful tool for organizational improvement. 
MEDIATORS FOR EMPOWERING LEADERSHIP EFFECTS 27

\section{References}

Ahearne, M., Mathieu, J., \& Rapp, A. (2005). To empower or not to empower your sales force? An empirical examination of the influence of leadership empowerment behavior on customer satisfaction and performance. Journal of Applied Psychology, 90, 945-955.

Allan, B. A., Autin, K. L., \& Duffy, R. D. (2016). Self-determination and meaningful work: Exploring socioeconomic constraints. Frontiers in Psychology, 7, 1-9.

Amundsen, S., \& Martinsen, Ø. L. (2014). Empowering leadership: Construct clarification, conceptualization, and validation of a new scale. The Leadership Quarterly, 25, 487-511.

Amundsen, S., \& Martinsen, Ø. L. (2015). Linking empowering leadership to job satisfaction, work effort, and creativity: The role of self-leadership and psychological empowerment. Journal of Leadership \& Organizational Studies, 22, 304-323.

Arnold, J. A., Arad, S., Rhoades, J. A., \& Drasgow, F. (2000). The empowering leadership questionnaire: The construction and validation of a new scale for measuring leader behaviors. Journal of Organizational Behavior, 21, 249-269.

Audenaert, M., Vanderstraeten, A., \& Buyens, D. (2017). When affective well-being is empowered: The joint role of leader-member exchange and the employment relationship. The International Journal of Human Resource Management, 28, 2208-2227.

Behrend, T. S., Sharek, D. J., Meade, A. W., \& Wiebe, E. N. (2011). The viability of crowdsourcing for survey research. Behavior Research Methods, 43, 800-813.

Bennett, R. J., \& Robinson, S. L. (2000). Development of a measure of workplace deviance. Journal of Applied Psychology, 85, 349-360.

Bennett, R. J., \& Robinson, S. L. (2003). The past, present, and future of workplace deviance research. In J. Greenberg (Eds.), Organizational behavior: The state of the science (pp. 247-281). Mahwah, New Jersey: Lawrence Erlbaum Associates. 
Blustein, D. L. (2008). The role of work in psychological health and well-being: A conceptual, historical, and public policy perspective. American Psychologist, 63, 228-240.

Bowling, N. A., Eschleman, K. J., Wang, Q., Kirkendall, C., \& Alarcon, G. (2010). A metaanalysis of the predictors and consequences of organization-based self-esteem. Journal of Occupational and Organizational Psychology, 83, 601-626.

Buhrmester, M., Kwang, T., \& Gosling, S. D. (2011). Amazon’s Mechanical Turk: A new source of inexpensive, yet high-quality, data? Perspectives on Psychological Science, 6, 3-5.

Casler, K., Bickel, L., \& Hackett, E. (2013). Separate but equal? A comparison of participants and data gathered via Amazon's MTurk, social media, and face-to-face behavioral testing. Computers in Human Behavior, 29, 2156-2160.

Chan, S. C., Huang, X., Snape, E., \& Lam, C. K. (2013). The Janus face of paternalistic leaders: Authoritarianism, benevolence, subordinates organization -based self-esteem, and performance. Journal of Organizational Behavior, 34, 108-128.

Cheong, M., Spain, S. M., Yammarino, F. J., \& Yun, S. (2016). Two faces of empowering leadership: Enabling and burdening. The Leadership Quarterly, 27, 602-616.

Cheung, J. H., Burns, D. K., Sinclair, R. R., \& Sliter, M. (2017). Amazon Mechanical Turk in organizational psychology: An evaluation and practical recommendations. Journal of Business and Psychology, 32, 347-361.

Cordery, J. L., Morrison, D., Wright, B. M., \& Wall, T. D. (2010). The impact of autonomy and task uncertainty on team performance: A longitudinal field study. Journal of Organizational Behavior, 31, 240-258.

Crawford, E. R., LePine, J., \& Rich, B. L. (2010). Linking job demands and resources to employee engagement and burnout. Journal of Applied Psychology, 95, 834-848. 
Deci, E. L., \& Ryan, R. M. (2000). The "what" and "why" of goal pursuits: Human needs and the self-determination of behavior. Psychological Inquiry, 11, 227-268.

DeSimone, J. A., Harms, P. D., \& DeSimone, A. J. (2015). Best practice recommendations for data screening. Journal of Organizational Behavior, 36, 171-181.

Dewettinck, K., \& van Ameijde, M. (2011). Linking leadership empowerment behavior to employee attitudes and behavioral intentions: Testing the mediating role of psychological empowerment. Personnel Review, 40, 284-305.

Diener, E., Emmons, R. A., Larsen, R. J., \& Griffin, S. (1985). The Satisfaction with life scale. Journal of Personality Assessment, 49, 71-75.

Diener, E., \& Fujita, F. (1995). Resources, personal strivings, and subjective well-being: A nomothetic and idiographic approach. Journal of Personality and Social Psychology, $68,926-935$.

Duffy, R. D., Dik, B. J., \& Steger, M. S. (2011). Calling and work related outcomes: Career commitment as a mediator. Journal of Vocational Behavior, 78, 210-218.

Ferris, D. L., Brown, D. J., \& Heller, D. (2009). Organizational supports and organizational deviance: The mediating role of organization-based self-esteem. Organizational Behavior and Human Decision Processes, 108, 279-286.

Gardner, D. G., \& Pierce, J. L. (2016). Organization-based self-esteem: Making a difference at work. In T. Duening (Ed.), Leading the positive organization: actions, tools, and processes (pp. 27-48). New York: Business Expert Press.

Goodman, J. K., Cryder, C. E., \& Cheema, A. (2013). Data collection in a flat world: The strengths and weaknesses of Mechanical Turk samples. Journal of Behavioral Decision Making, 26, 213-224. 
MEDIATORS FOR EMPOWERING LEADERSHIP EFFECTS 30

Grant, A. M. (2007). Relational job design and the motivation to make a prosocial difference. Academy of Management Review, 32, 393-417.

Greenhaus, J. H., \& Powell, G. N. (2006). When work and family are allies: A theory of workfamily enrichment. Academy of Management Review, 31, 72-92.

Hackman, J. R., \& Oldham, G. R. (1980). Work redesign. Reading, MA: Addison-Wesley.

Harris, K. J., Kacmar, K. M., \& Zivnuska, S. (2007). An investigation of abusive supervision as a predictor of performance and the meaning of work as a moderator of the relationship. The Leadership Quarterly, 18, 252-263.

Hayes, A. F. (2013). Introduction to mediation, moderation, and conditional process analysis: A regression-based approach. New York, NY: Guilford Press.

Hays, R. D., Hayashi, T., \& Stewart, A. L. (1989). A five-item measure of socially desirable response set. Educational and Psychological Measurement, 49, 629-636.

Hobfoll, S. E. (1989). Conservation of resources: A new attempt at conceptualizing stress. American Psychologist, 44, 513-524.

Hobfoll, S. E. (2001). The influence of culture, community, and the nested-self in the stress process: Advancing conservation of resources theory. Applied Psychology, 50, 337-421.

Jöreskog, K. G., \& Sörbom, D. (2006). LISREL 8.8 [computer software]. Lincolnwood, IL: Scientific Software International.

Judge, T. A., \& Watanabe, S. (1994). Individual differences in the nature of the relationship between job and life satisfaction. Journal of Occupational and Organizational Psychology, 67, 101-107.

Kahn, W. A. (2007). Meaningful connections: Positive relationships and attachments at work. In J. E. Dutton \& B. R. Ragins (Eds.), Exploring positive relationships at work: Building a 
MEDIATORS FOR EMPOWERING LEADERSHIP EFFECTS 31

theoretical and research foundation (pp. 189-206). Mahwah, NJ: Lawrence Erlbaum Associates.

Kees, J., Berry, C., Burton, S., \& Sheehan, K. (2017). An analysis of data quality: Professional panels, student subject pools, and Amazon's Mechanical Turk. Journal of Advertising, 46, $141-155$.

Kim, M., \& Beehr, T. A. (2017a). Directing our own careers, but getting help from empowering leaders, Career Development International, 22, 300-317.

Kim, M., \& Beehr, T. A. (2017b). Self-efficacy and psychological ownership mediate the effects of empowering leadership on both good and bad employee behaviors, Journal of Leadership \& Organizational Studies, 24, 466-478.

Kim, M., \& Beehr, T. A. (2017c). Can empowering leaders affect subordinates' well-being and careers because they encourage subordinates' job crafting behaviors? Journal of Leadership \& Organizational Studies, Advance online publication. https://doi.org/10.1177/1548051817727702

Kim, M., Beehr, T. A., \& Prewett, M. S. (2018). Employee responses to empowering leadership: A meta-analysis, Journal of Leadership \& Organizational Studies. Advance online publication. https://doi.org/10.1177/1548051817750538

Konczak, L. J., Stelly, D. J., \& Trusty, M. L. (2000). Defining and measuring empowering leader behaviors: Development of an upward feedback instrument. Educational and Psychological Measurement, 60, 301-313.

Marstand, A. F., Martin, R., \& Epitropaki, O. (2017). Complementary person-supervisor fit: An investigation of supplies-values (SV) fit, leader-member exchange (LMX) and work outcomes. The Leadership Quarterly, 28, 418-437. 
Martin, S. L., Liao, H., \& Campbell, E. M. (2013). Directive versus empowering leadership: A field experiment comparing impacts on task proficiency and proactivity. Academy of Management Journal, 56, 1372-1395.

Maslach, C., Schaufeli, W. B., \& Leiter, M. P. (2001). Job burnout. Annual Review of Psychology, 52, 397-422.

Mason, W., \& Suri, S. (2012). Conducting behavioral research on Amazon’s Mechanical Turk. Behavior Research Methods, 44, 1-23.

Maynard, M. T., Gilson, L. L., \& Mathieu, J. E. (2012). Empowerment—fad or fab? A multilevel review of the past two decades of research. Journal of Management, 38, 12311281.

Maynard, M. T., Luciano, M. M., D’Innocenzo, L., Mathieu, J. E., \& Dean, M. D. (2014). Modeling time-lagged reciprocal psychological empowerment-performance relationships. Journal of Applied Psychology, 99, 1244-1253.

McAllister, D. J., \& Bigley, G. A. (2002). Work context and the definition of self: How organizational care influences organization-based self-esteem. Academy of Management Journal, 45, 894-904.

McDowell, I. (2010). Measures of self-perceived well-being. Journal of Psychosomatic Research, 69, 69-79.

Myers, D. G., \& Diener, E. (1995). Who is happy? Psychological Science, 6, 10-19.

Naus, F., van Iterson, A., \& Roe, R. A. (2007). Value incongruence, job autonomy, and organization-based self-esteem: A self-based perspective on organizational cynicism. European Journal of Work and Organizational Psychology, 16, 195-219. 
Peer, E., Vosgerau, J., \& Acquisti, A. (2014). Reputation as a sufficient condition for data quality on Amazon Mechanical Turk. Behavior Research Methods, 46, 1023-1031.

Pierce J. L., \& Gardner, D. G. (2004). Self-esteem within the work and organizational context: A review of the organization-based self-esteem literature. Journal of Management, 30, $591-622$.

Pierce, J. L., Gardner, D. G., Cummings, L. L., \& Dunham, R. B. (1989). Organization-based self-esteem: Construct definition, measurement, and validation. Academy of Management Journal, 32, 622-648.

Pines, A. M., \& Zaidman, N. (2014). Stress and burnout in bicultural teams in hi-tech industry. British Journal of Management, 25, 819-832.

Podsakoff, P. M., MacKenzie, S. P., \& Podsakoff, N. P. (2012). Sources of method bias in social science research and recommendations on how to control it. Annual Review of Psychology, 63, 539-569.

Pratt, M. G., \& Ashforth, B. E. (2003). Fostering meaningfulness in working and at work. In K. S. Cameron, J. E. Dutton, \& R. E. Quinn (Eds.), Positive organizational scholarship (pp. 309-327). San Francisco: Berrett-Koehler Publishers.

Preacher, K. J., \& Kelley, K. (2011). Effect size measures for mediation models: Quantitative strategies for communicating indirect effects. Psychological Methods, 16, 93-115.

Ramsey, S. R., Thompson, K. L., McKenzie, M., \& Rosenbaum, A. (2016). Psychological research in the internet age: The quality of web-based data. Computers in Human Behavior, 58, 354-360. 
Randolph, W. A., \& Kemery, E. R. (2011). Managerial use of power bases in a model of managerial empowerment practices and employee psychological empowerment. Journal of Leadership \& Organizational Studies, 18, 95-106.

Rosso, B. D., Dekas, K. H., \& Wrzesniewski, A. (2010). On the meaning of work: A theoretical integration and review. Research in Organizational Behavior, 30, 91-127.

Schaufeli, W. B., Leiter, M. P., Maslach, C., \& Jackson, S. E. (1996). The Maslach Burnout Inventory-GS. In C. Maslach, S. E. Jackson, \& M. P. Leiter (Eds.), Maslach Burnout Inventory Manual (pp. 22-26). Palo Alto, CA: Consulting Psychologists Press.

Sekiguchi, T., Burton, J. P., \& Sablynski, C. J. (2008). The role of job embeddedness on employee performance: The interactive effects with leader-member exchange and organization-based self-esteem. Personnel Psychology, 61, 761-792.

Seibert, S. E., Wang, G., \& Courtright, S. H. (2011). Antecedents and consequences of psychological and team empowerment in organizations: A meta-analytic review. Journal of Applied Psychology, 96, 981-1003.

Spreitzer, G. M. (1995). Psychological empowerment in the workplace: Dimensions, measurement, and validation. Academy of Management Journal, 38, 1442-1465.

Steel, P., Schmidt, J., \& Shultz, J. (2008). Refining the relationship between personality and subjective well-being. Psychological Bulletin, 134, 138-161.

Steger, M. F., \& Dik, B. J. (2009). If one is searching for meaning in life, does meaning in work help? Applied Psychology: Health and Well-Being, 1, 303-320.

Steger, M. F., \& Dik, B. J. (2010). Work as meaning: Individual and organizational benefits of engaging in meaningful work. In P. A. Linley, S. Harrington, \& N. Garcea (Eds.), Oxford 
MEDIATORS FOR EMPOWERING LEADERSHIP EFFECTS 35

handbook of positive psychology and work (pp. 131-142). Oxford: Oxford University Press.

Steger, M. F., Dik, B. J., \& Duffy, R. D. (2012). Measuring meaningful work: The Work as Meaning Inventory (WAMI). Journal of Career Assessment, 20, 322-337.

Steger, M. F., Littman-Ovadia, H., Miller, M., Menger, L., \& Rothmann, S. (2013). engaging in work even when it is meaningless: Positive affective disposition and meaningful work interact in relation to work engagement. Journal of Career Assessment, 21, 348-361.

Sumpter, D. M., Gibson, C. B., \& Porath, C. (2016). Act expediently, with autonomy: Vicarious learning, empowered behaviors, and performance. Journal of Business and Psychology, $1-15$.

Tang, G., Kwan, H. K., Zhang, D., \& Zhu, Z. (2016). Work-family effects of servant leadership: The roles of emotional exhaustion and personal learning. Journal of Business Ethics, 137, 285-297.

Thau, S., Aquino, K., \& Poortvliet, P. M. (2007). Self-defeating behaviors in organizations: The relationship between thwarted belonging and interpersonal work behaviors. Journal of Applied Psychology, 92, 840-847.

Tuckey, M. R., Bakker, A. B., \& Dollard, M. F. (2012). Empowering leaders optimize working conditions for engagement: A multilevel study. Journal of Occupational Health Psychology, 17, 15-27.

Van Dyne, L., Vandewalle, D., Kostova, T., Latham, M. E., \& Cummings, L. L. (2000). Collectivism, propensity to trust and self-esteem as predictors of organizational citizenship in a non-work setting. Journal of Organizational Behavior, 21, 3-23. 
Vecchio, R. P., Justin, J. E., \& Pearce, C. L. (2010). Empowering leadership: An examination of mediating mechanisms within a hierarchical structure. The Leadership Quarterly, 21, $530-542$.

Watson, D., Clark, L. A., \& Tellegen, A. (1988). Development and validation of brief measures of positive and negative affect: The PANAS scales. Journal of Personality and Social Psychology, 54, 1063-1070.

Whelpley, C. E., \& McDaniel, M. A. (2016). Self-esteem and counterproductive work behaviors: A systematic review. Journal of Managerial Psychology, 31, 850-863.

Williams, L. J., \& Anderson, S. E. (1991). Job satisfaction and organizational commitment as predictors of organizational citizenship and in-role behaviors. Journal of Management, 17, 601-617.

Wrzesniewski, A., Dutton, J. E., \& Debebe, G. (2003). Interpersonal sensemaking and the meaning of work. In R. M. Kramer \& B. M. Staw (Eds.), Research in organizational behavior (pp. 93-135). Amsterdam: Elsevier.

Zhang, X., \& Bartol, K. M. (2010). Linking empowering leadership and employee creativity: The influence of psychological empowerment, intrinsic motivation, and creative process engagement. Academy of Management Journal, 53, 107-128. 
Table 1

Descriptive Statistics and Correlations

\begin{tabular}{|c|c|c|c|c|c|c|c|c|c|c|c|}
\hline Variables & Mean & $S D$ & $\alpha$ & 1 & 2 & 3 & 4 & 5 & 6 & 7 & 8 \\
\hline $\begin{array}{l}\text { 1. Empowering } \\
\text { Leadership (T1) }\end{array}$ & 3.81 & 0.66 & .90 & & & & & & & & \\
\hline $\begin{array}{l}\text { 2. Organization-Based } \\
\text { Self-Esteem (T2) }\end{array}$ & 5.79 & 0.78 & .91 & $.45^{* *}$ & & & & & & & \\
\hline 3. Meaningful Work (T2) & 5.01 & 1.41 & .96 & $.40^{* *}$ & $.59^{* *}$ & & & & & & \\
\hline $\begin{array}{l}\text { 4. Organizational } \\
\text { Citizenship Behavior (T3) }\end{array}$ & 5.44 & 0.79 & .84 & $.24 * *$ & $.44^{* *}$ & $.24^{* *}$ & & & & & \\
\hline $\begin{array}{l}\text { 5. Deviant } \\
\text { Behavior (T3) }\end{array}$ & 1.90 & 0.82 & .94 & -.06 & $-.14 * *$ & -.10 & $-.51 * *$ & & & & \\
\hline $\begin{array}{l}\text { 6. Emotional } \\
\text { Exhaustion (T3) }\end{array}$ & 3.42 & 1.86 & .95 & $-.37 * *$ & $-.25 * *$ & $-.28 * *$ & -.08 & .00 & & & \\
\hline 7. Life Satisfaction (T3) & 4.93 & 1.45 & .92 & $.26^{* *}$ & $.27 * *$ & $.31 * *$ & $.15^{* *}$ & -.02 & $-.49 * *$ & & \\
\hline 8. Negative Affectivity (T2) & 1.65 & 0.70 & .92 & $-.17 * *$ & $-.17 * *$ & $-.12 *$ & $-.16^{* *}$ & $.23 * *$ & $.32 * *$ & $-.30 * *$ & \\
\hline 9. Social Desirability (T2) & 3.42 & 0.84 & .73 & $.12 *$ & $.20 * *$ & .05 & $.37 * *$ & $-.28 * *$ & -.04 & .02 & $-.18 * *$ \\
\hline
\end{tabular}

Notes: $N=347$.

$* p<.05$

$* * p<.01$ 
Table 2

Summary of Model Fit Indices

\begin{tabular}{lllllllllllll}
\hline Model Test & $\chi^{2}$ & $d f$ & RMSEA & CFI & NNFI & IFI & $\Delta \chi^{2}$ & $\Delta d f$ & $p$ \\
\hline
\end{tabular}

Measurement Model

$1147.98 \quad 428$

.07

$.96 \quad .95$

.96

Hypothesized Model

$1461.33 \quad 454 \quad .08$

$.94 \quad .93$

.94

Alternative Model 1: Adding 2 paths from OBSE to psychological wellbeing and 2 paths from meaningful

work to work behaviors

Alternative Model 2: Adding 4 direct paths from empowering leadership to work behaviors and psychological well-being

Note: $\chi^{2}$-values for the structural models are significant at $p<.01$. Work behaviors include organizational citizenship behavior and deviant behavior. Psychological well-being includes emotional exhaustion and life satisfaction. OBSE is organization-based selfesteem. 
Table 3

Results of Bootstrapping Tests for Estimating Indirect Effects with 95\% Confidence Intervals

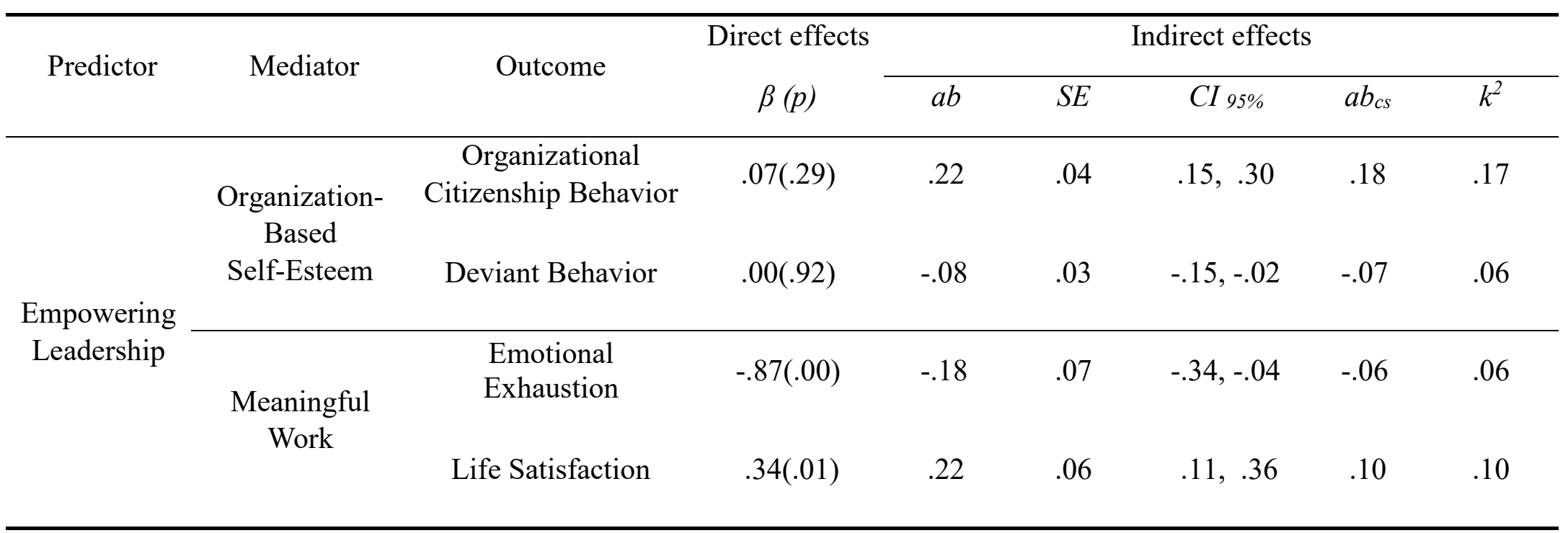

Note: $N=347 . \beta=c^{\prime}$ (direct effect). $a b=$ unstandardized indirect effect. $S E=$ bootstrap standard error. $a b, S E$, and $C I$ 95\% were obtained from 10,000 bootstrap samples. $a b_{c s}=$ completely standardized indirect effect. $k^{2}=$ indirect effect $/$ maximum possible mediation. 
Time 1

Time 2

Time 3

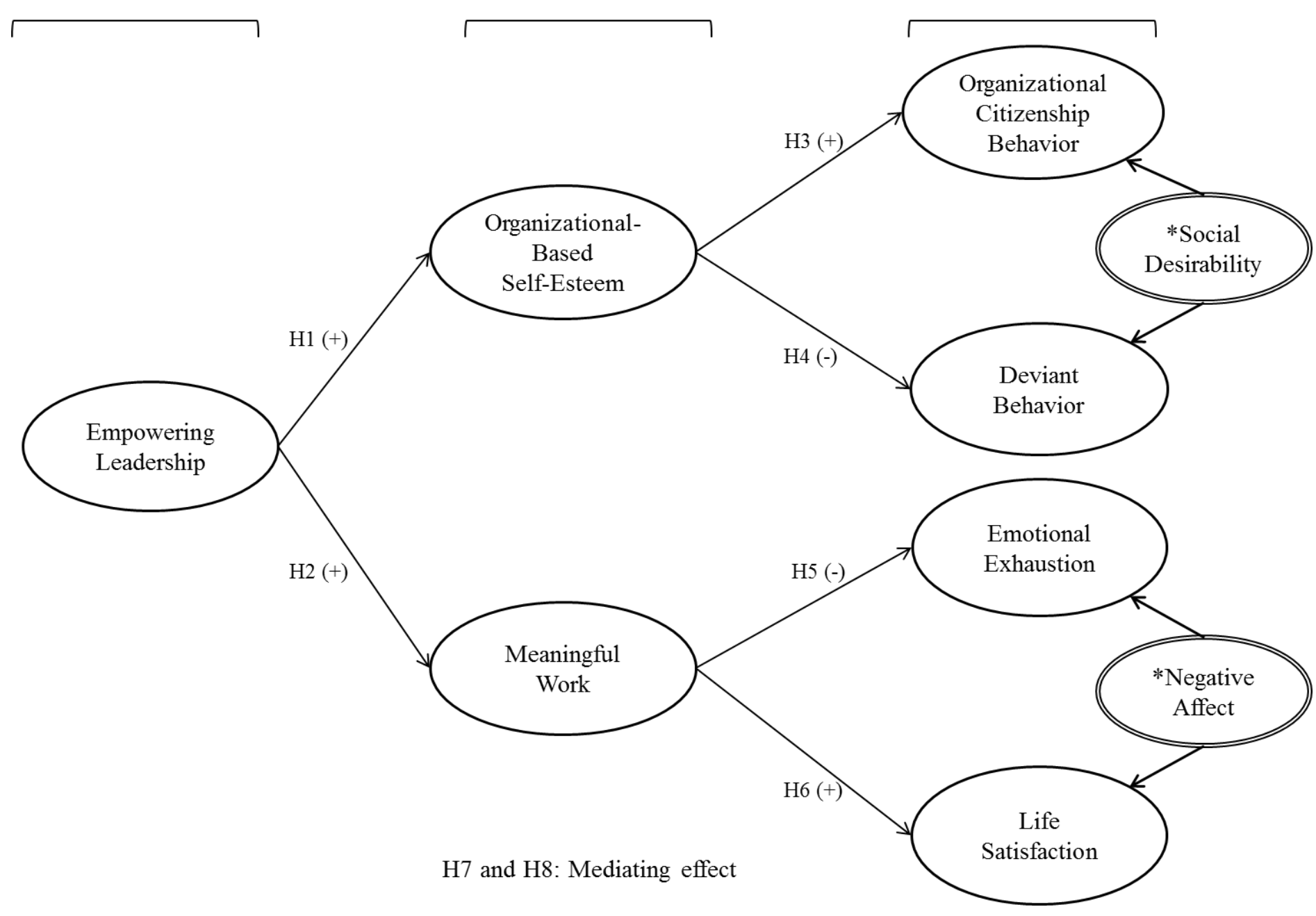

Figure 1. Hypothesized model

*Note: Double circle indicates control variables. 
Empowering

Leader Behaviors

Resources

Work Behaviors and Well-Being

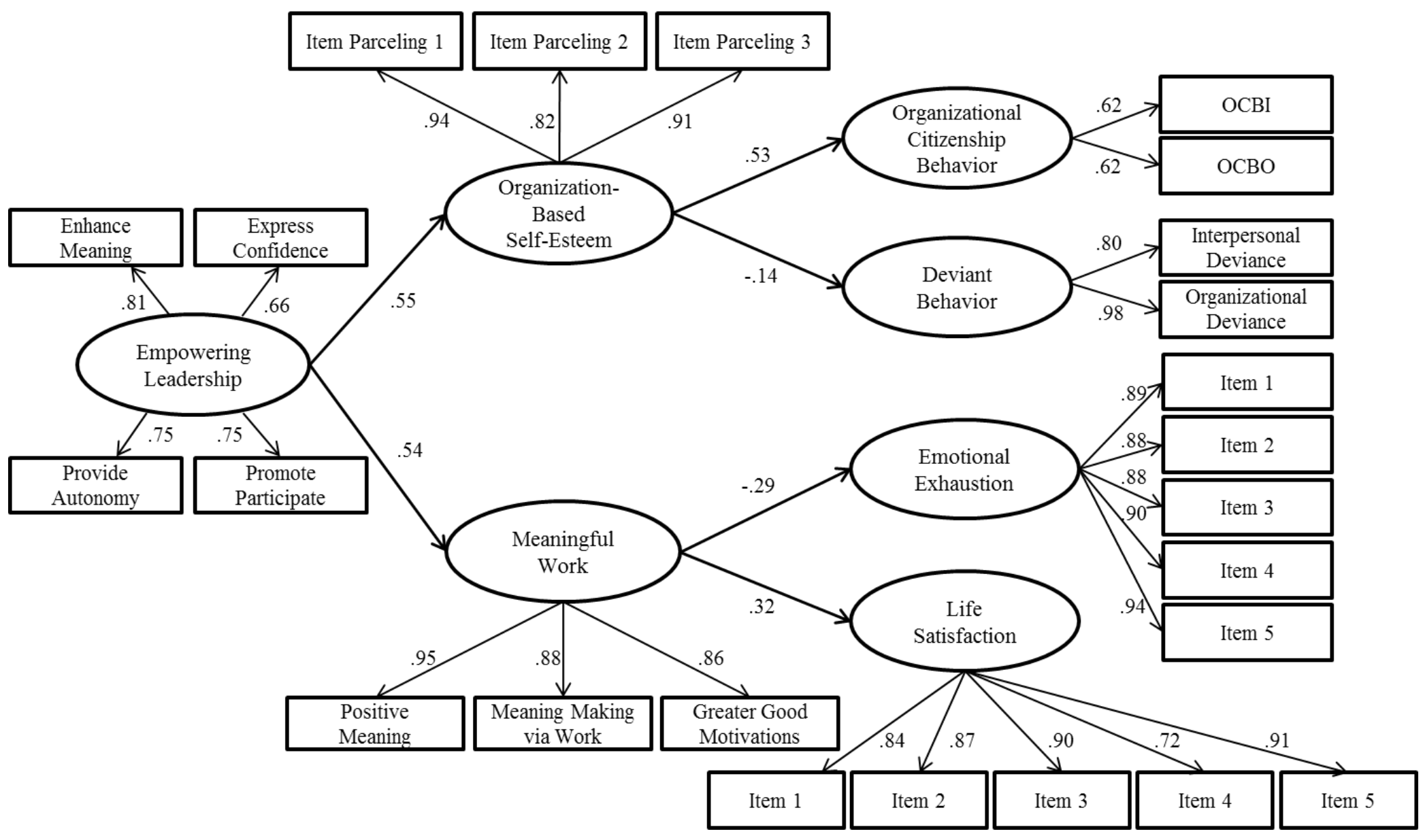

Figure 2. Structural equation model with standardized coefficients

Note: All paths in structural model analysis are significant at $p<.01$. Control variables are not shown in order to increase readability. 